\title{
Complexation of heavy metal ions with peat humic acids
}

Lodygin E.D. ${ }^{1}$, Alekseev I.I. ${ }^{2}$, Vasilevich R.S. ${ }^{1}$, Abakumov E.V. ${ }^{2}$

${ }^{1}$ Institute of Biology, Komi Science Center, Ural Branch, Russian Academy of Sciences, Syktyvkar, Russia, lodigin@ib.komisc.ru

${ }^{2}$ Saint Petersburg State University, Saint Petersburg, Russia

doi: 10.36291/HIT.2019.lodygin.037

Based on a model experiment, the binding ability of humic acids (HAs) of Hemic Folic Cryic Histosol (peat with vegetated plots) to lead and cadmium ions was revealed. It has been shown that the process of adsorption of metal ions by suspended humic acids is similar to the process of complexation of metal ions with certain functional groups of dissolved HAs. This trend follows the Irving-Williams series, which describes the stability order of metal complexes. For humic acids, the stability of complexes with dipositive metal ions is of the following order: $\mathrm{Pb}^{2+}>\mathrm{Cd}^{2+}$, which is partly due to a decrease in the ionic size and the effects of the ligand field. The thermodynamic characteristics (limiting specific adsorption, constant of sorption equilibrium, Gibbs energy, entropy and thermal effect of sorption) of the adsorption process of selected heavy metal ions are calculated. It was found that the critical specific adsorption of $\mathrm{Pb}^{2+}$ ions is almost an order of magnitude higher than that of $\mathrm{Cd}^{2+}$ ions and amounts to $0.0078-0.034 \mathrm{mmol} / \mathrm{L}_{\text {for }} \mathrm{Cd}^{2+}$ ions and $0.16-0.29 \mathrm{mmol} / \mathrm{L}$ for $\mathrm{Pb}^{2+}$ ions. The changes in the sorption enthalpy are $48.4 \mathrm{~kJ} / \mathrm{mol}$ for $\mathrm{Cd}^{2+}$ ions and $22.6 \mathrm{~kJ} / \mathrm{mol}$ for $\mathrm{Pb}^{2+}$ ions indicate the endothermic nature of adsorption on HAs preparations. This is due to the chemisorption processes. A large amount of heat is spent on the destruction of the hydration shell of metal ions, which is confirmed by the positive values of the change in sorption entropy. It was shown that the limiting stage of adsorption for $\mathrm{Pb}^{2+}$ ions is the stage of ion diffusion to the sorbent, and chemosorption itself proceeds quite quickly. Values of $\Delta S>-10 \mathrm{~J} /(\mathrm{mol} \cdot \mathrm{K})$ indicate a dissociative adsorption mechanism for both metals, i.e. non-adsorbed ions in solution are in a more ordered state than after adsorption. Negative values of the Gibbs energy change for $\mathrm{Cd}^{2+}$ and $\mathrm{Pb}^{2+}$ ions indicate that the adsorption of $\mathrm{Cd}^{2+}$ and $\mathrm{Pb}^{2+}$ ions by humic acid preparations of peat soils is a spontaneous process with a complex mechanism including complexation and ion exchange processes.

Acknowledgements. The reported study was funded by RFBR according to the research projects № 18-31-00001 (molecular composition of humic acids) and № 19-3450015 (sorption properties of humic acids). 